\title{
Intersectionality, Structural Vulnerability, and Access to Sexual and Reproductive Health Services: Filipina Domestic Workers in Hong Kong, Singapore, and Qatar
}

\author{
Thanh-Dam Truong, ${ }^{1}$ Maria Lourdes S. Marin, ${ }^{2}$ and Amara Quesada-Bondad ${ }^{3}$
}

\begin{abstract}
In this chapter the experiences of Filipina domestic workers in Hong Kong, Singapore, and Qatar are examined in the framework of their structural vulnerability to health problems. The chapter shows how their poor state of Sexual and Reproductive Health (SRH) can be the outcome of a combination of forms of institutional discrimination that are interconnected and should be investigated in respect of: (a) the worth of their 'identity' (migrant, female, the work they do); (b) the distinct aspects of discourse on sexuality and normativity which specifically relate to their presence in the destination countries; and (c) ideational and material realities constraining their own agency in finding adequate care. The chapter shows how variations in the potential for access may be explained by the types and degree of their structural vulnerability regarding labour rights, their relationship with employers and migrants' associations, and their personal SRH awareness-together with what emerges from cooperation between those government officials and civil society organizations who work with migrant domestic workers. Attentiveness to the particular combination of forms of institutional discrimination in a given cultural and institutional context, especially the ways in which the Sexual and Reproductive Health of Filipina domestic workers are linked to the ways in which labour migration are organized, should be helpful for effective SRH advocacy.
\end{abstract}

Keywords: Filipina Domestic Workers, Hong Kong, Singapore, Qatar, Sexual and Reproductive Health, Advocacy, Structural Vulnerability, institutional Discrimination, Sexuality.

\subsection{Introduction}

Health control in international migration has historically been driven by the concern of receiving states to screen newcomers for disease in the interest of protecting their citizens from health risks. This has led to the tendency for migrants to be portrayed by some ac-

1 Dr Thanh-Dam Truong is Associate Professor in Women/Gender and Development Studies at the International Institute of Social Studies, Erasmus University Rotterdam (The Netherlands).

2 Ms Maria Lourdes S. Marin is the Executive Director of Action for Health Initiatives (ACHIEVE), Inc., a Philippines-based organization working on migration, gender, and health issues.

3 Ms Amara Quesada-Bondad has been the Programme Officer of ACHIEVE in Quezon City in The Philippines since $200 I$. tors involved as a risk to public health. In recent years the global campaign for the right to health as a fundamental human right has opened the way for civil society organizations and scholars to develop and establish an approach to the health needs of labour migrants which enables their voices to be heard and properly addressed (WHO 20IO). The plight of labour migrants who occupy the range of occupations in the global economy defined as low-skilled or unskilled (often with temporary contractual arrangements, or in sectors not covered by labour protection laws in either the sending or destination countries, or both) has become a major concern from the standpoint of social justice in health (Dwyer 2004). The fragmented understanding of sexuality in health matters calls for more creative cooperation between health research and migration research to steer policy agendas towards providing more appropriate responses to the SRH needs of labour migrants. 
Uncovering the complex relationship between migration and health (particularly how the operation of certain migration systems these days can have a serious impact on the occupational and personal health of transnational labour migrants) requires a revision of the ways of understanding labour migration. Most policy and research concerning migration presents a prototype of the labour migrant as a unit in the macroeconomic theory of exchange, and focuses on financial gains and losses rather than on the realities as lived by migrants. More attentiveness and openness to how life actually is for people on the move across borders, and to the patterns of their inclusion in and exclusion from societies, is crucial for an effective approach to their right to health in line with international human rights law. ${ }^{4}$

Sexual and Reproductive Health (SRH) is a relatively new field of inquiry in migration research. Here, we take a holistic approach and explore how a combination of forms of institutional discrimination that are interconnected can affect how SRH problems are solved for migrant domestic workers. First, the concept of SRH is set out as a normative framework, and this is followed by a discussion on the concept of structural vulnerability to ill health that has been introduced in medical anthropology and applied to the situations of marginal labour migrants. This concept is then adjusted for the analysis of SRH situations faced by domestic workers from the Philippines in Hong Kong, Singapore, and Qatar. Data compiled on the experiences of migrant women domestic workers during their years of employment in these destination countries are presented, and the variations discussed. ${ }^{5}$ The conclusion proposes new avenues for SRH advocates to take on board the needs of mobile populations in a globalized world and to cooperate with mi-

4 The International Covenant on Economic, Social and Cultural Rights, art. I2; the 1965 International Convention on the Elimination of All Forms of Racial Discrimination, art. 5(e)(iv); the 1966 International Covenant on Economic, Social and Cultural Rights, art. I2; the 1979 Convention on the Elimination of All Forms of Discrimination against Women: arts. II(I)(f), I2, and I4(2)(b); The 1989 Convention on the Rights of the Child, art. 24; the 1990 International Convention on the Protection of the Rights of All Migrant Workers and Members of Their Families: arts. 28, 43(e) and 45(c); the 2006 Convention on the Rights of Persons with Disabilities, art. 25. See at: <http://www.ohchr.org/Documents/Publications/Factsheet31.pdf $>$ (accessed I9 July ○০০০). gration researchers, so that they can promote appropriate responses to migrant workers' health needs.

\subsection{Understanding SRH from the Perspective of Intersectionality and Structural Vulnerability}

The Report of the 1994 Cairo International Conference on Population and Development (ICPD) includes a definition of Reproductive Health as:

[T]he state of complete physical, mental and social wellbeing and not merely the absence of disease or infirmity, in all matters relating to the reproductive system and to its functions and processes. Reproductive health therefore implies that people are able to have a satisfying and safe sex life and that they have the capability to reproduce and the freedom to decide if, when and how often to do so. 6

Three other concepts associated with this definition are: (I) reproductive health care as the constellation of methods, techniques, and services contributing to (2) reproductive health and well-being (through prevention and remedy to reproductive health problems); (3) sexual health as enhancement of life and personal relations (beyond and above an understanding limited to counselling and care related to reproduction and sexually transmitted diseases).

Glasier, Gülmezoglu, Schmid, Moreno, and Look (2006) point out that SRH encompasses the totality of a person's sexual and gendered existence, and involves multiple and overlapping domains: the body, social identity, beliefs, attitudes, expressions, behaviour, and the social relationships through which desires are expressed and health is ensured. Although the majority of sexual and reproductive health issues affect women, men are also subject to such health risks, and are party to many of the related methods, techniques, and services that ensure healthy lives. It should be emphasized that sexual and reproductive health is not only about illness and disease but also

5 The data presented in this chapter were collected between 2008 and 2010 in the framework of a research project funded by IDRC, project number: I05637-00I, and entitled: "The Health of Our Heroes: A Qualitative Study on Access to Sexual and Reproductive Health Services and Information of Women Migrant Domestic Workers". Field research conducted by ACHIEVE, Inc. has been supplemented by desk research.

6 UN Report of the International Conference on Population and Development, Cairo, 5-I3 September 1994, United Nations, New York (1995). Sales No. 95.XIII.I8. 
about "a collection of related health and human rights issues and many people are still confused about what it [SRH] consists of" [italics added] (Glasier/Gülmezoglu/Schmid/Moreno/Look 2006: I604). This ambiguity has significant implications for SRH advocates (in respect of migrant populations) as well as for migrants themselves. In particular, SRH advocacy is very limited for workers on temporary contracts in countries where their work is not included in the labour law provisions, and where there is limited social consciousness of the significance of SRH generally and within a person's emotional life specifically.

As they are mostly of reproductive age, women migrant workers do not become sexually inactive once they cross a national border. Though loneliness and homesickness are common for newly arrived and firsttime migrant workers, for those who have had to leave their families and partners for work many times, periodical yearnings for intimacy and for the feeling of 'being home' socially and sexually continue to occur (Marin 20I2). Having to manage an existence which stretches between different localities with multiple identities-citizen, migrant, worker, wife, husband, intimate partner, son, daughter-these migrant workers also must renegotiate meanings of love, loyalty, and affection at a distance, while simultaneously establishing a new set of social bonds in their new place. Emotional expression in such a context requires the careful consideration of the specific social boundaries defined by the time-bound nature of their stay, the intersubjective and cultural meanings of intimacy, and the consequences they must face when transgressing the norms of propriety related to SRH at the place of their employment (Marin 20I2). Knowledge about the SRH of migrant domestic workers as a social group cannot be gained from a specific position declared as 'universal'. It requires the unravelling of many layers of power in different places that shape migrants' overlapping social identities and sense of belonging, layers which define the right to reveal their SRH needs and entitlement to care services.

The World Health Organization's report on the health of migrants (2008) notes that migrants travel with their epidemiological profiles, their level of exposure to infectious agents, their susceptibility to certain conditions, and their genetic and lifestyle-related risk factors, along with their culture-based health beliefs. They also travel with their sexual histories and SRH notions and practices. Access to health and medical services not only has a direct impact on their health outcomes but also on a range of other indirect benefits at the societal level: a healthier society with fewer burdens on public services caused by the progressive complications of health problems (Gushulak 20IO).

A useful source of ideas about public health activism in the field of SRH for migrant domestic workers may be found in Farmer's pioneering work (2004) on the pathological workings of power relations in the health sector. Using the concept of structural violence, borrowed from Galtung (1990), Farmer shows how denial of access to health treatment is systemically embedded in social structures, and how poor health outcomes among certain population groups can be the result of numerous processes of marginalization by governments, health sector officials, and industry, combined with microdynamics intersecting class, gender, age, ethnicity, and other criteria of belonging.

Criticism of Farmer's overemphasis on macrostructures calls for more nuanced understanding of access to health, shaped by more subtle processes of differentiation in the social distribution of well-being and illness. Quesada, Hart, and Bourgois (20I2: 34I) identify the following: I) the formation of social hierarchies buttressed by a hierarchy of symbolic meanings of worthiness (Bourdieu 2000); and 2) historically distinctive discourses of normativity and sexual ethics (Foucault 1979). In this way, they redefine the concept of 'structural violence' as 'structural vulnerability' in respect of ill health. In the light of Bourdieu's concept of positionality, structural vulnerability to ill health may be seen as produced by an individual's location in a given hierarchical social order that either enables or constrains the ability to act, negotiate, and change those contextually specific power relations affecting personal health. Quesada, Hart, and Bourgois (20I2) suggest that positionality-defined as the interplay between subjective and objective-can help bridge the binary distinction between structure and agency in order to give more visibility to the socially learned dispositions, skills, and ways of acting that are often taken for granted, but which are acquired primarily through the activities and accumulated experiences of everyday life.

Research into health among particular groups of immigrants, undocumented migrants, and transient migrant workers has shown a heterogeneity in the degree to which transnational migrant workers are vulnerable to ill health (Derose/Escarce/Lurie 2007; Lorant/Van Oyen/Thomas 2007). The key question is whether this heterogeneity reflects the functioning of health care systems per se, or whether there are, indeed, barriers to health services which may well be the outcome of the ways labour migration pro- 
grammes are organized - and thus shape workers' agency and health-seeking behaviour as well as access to services. This brings up the relevance of the concept of intersectionality as (I) a combination of forms of institutional discrimination (gender, age, migrant status, and ethnicity) that are interconnected and cannot be examined separately, and (2) the link between a labour migration system and a health care system.

As they are on temporary contracts, migrant workers often circulate between different places of employment and their home countries. Health insurance systems in their countries of origin may not cover expenses abroad and insurance in the host countries may not be easily affordable, particularly for lowskilled workers. Low-cost health insurance applicable across borders does not exist in many countries, and where it does there are major limitations. ${ }^{7}$

Even when their health status is cleared before departure, once on the move the employment situation of migrant workers in their destination countries becomes what basically underlies their overall state of well-being. It defines the boundaries of their new environment and its social connectivity, which in turn can directly and indirectly affect many aspects of their health physically and psycho-emotionally. Those who are undocumented, or have an 'irregular' status, are particularly disadvantaged and deprived because of their social invisibility. Lacking social and legal protection from frequent violence and abuse at the workplace, they run the risk of arrest and deportation when accessing public health systems. Seeking private health service providers with steeper costs, turning to self-medication, or experimenting with indigenous or alternative practices are basically the only options they have when encountering health problems (Marin 20I2).

There is a real and pressing need to understand structural vulnerability as produced by a combination of interconnected forms of institutional discrimination and by the link between migration systems and health systems. The right to health as built into international human rights law has no meaning until migrants can exercise them. Advocacy approaches to SRH justice for migrant domestic workers would ben-

7 For example, the Sekuye plan health insurance covers medical care in both the USA and Mexico, and the option to have treatment in Mexico. This will probably only be attractive to frequent migrants or those living near the border. The plan does not cover emergency medical costs. See at: <http://healthcare-economist.com/2008/02/28/cross-border-health-insurance/> (accessed Io May 20I2). efit from a full understanding of exclusion/inclusion processes which occur through finely-differentiated modes of power embedded in different contexts and workplaces.

\subsection{Power, Transience, and the Structural Vulnerability of Domestic Workers to SRH Problems}

The structural vulnerability of domestic workers to $\mathrm{SRH}$ problems may be conceptualized as an outcome of a process which hinges upon the following: I) the normative discourse about the body and sexuality which frames SRH and its application to the situation of domestic workers as a group; 2) cultural, social, and legal definitions of a domestic worker in the host country that define their social location and the corresponding consciousness and sense of accountability for their right to health care; and 3) the ways in which individual SRH problems are connected with practices at the workplace, which in turn, define their inclusion or exclusion from available and affordable health programmes and services.

Advocating for the SRH rights of migrant domestic workers faces major challenges. Given the wide definition of SRH, few countries can afford a comprehensive strategy. SRH services are mainly organized through a piecemeal approach, with the exception of education. Much depends on socio-demographic factors and the actual SRH problems which surface, and on budgetary constraints and the level of cooperation between health departments and civil society organizations. Attentiveness to social groups whose identities are invisible within the public realm does help influence the provision of services.

As a labour-sending country the Philippines has one of most rigorous policies and programmes in the world for protecting the rights of its citizens who work overseas. It has recently identified domestic workers as one of the main groups to be protected from violation of rights, along with entertainers and seafarers. ${ }^{8}$ Action in the SRH domain has been hampered by the position of the Catholic Church, which has conflated fertility management and use of contraception with abortion, leading to its vigorous opposition to the passage of the Reproductive Health Bill in the Congress of the Philippines. The church hierarchy, represented by the Catholic Bishops' Conference of the Philippines (CBCP), has consistently put pressure on the state regarding matters of sexuality and re- 
productive health. So therefore, despite formal commitments made by the government to implement international standards on $\mathrm{SRH},{ }^{9}$ programmes have mainly been supported by international development organizations. ${ }^{10}$ The resulting absence of a national policy on SRH hampers the implementation of comprehensive and concerted programmes within the country, and undermines the commitment to the sexual and reproductive well-being of overseas workers.

Efforts from civil society organizations and some local government units have been made to provide services that cover all the ten elements of reproductive health recognized by the Philippine government. But these remain far from the international normative framework of SRH rights. Family planning services are available in most public health facilities but with

8 The Republic Act No. 8042 puts together the national policies on overseas employment and establishes a higher standard of protection and promotion of the welfare of migrant workers, their families, and overseas Filipinos in distress. Together with the amendatory law RA I0022 of 2009 it defines in more concrete terms the diplomatic and consular duties of the Department of Foreign Affairs (DFA) and its embassies abroad. In 2009 the total number of contracts processed for Overseas Filipino Workers (OFWs), reported by the Philippine Overseas Employment Administration (POEA) for both rehires and new hires reached I,479,070. Of these, $7 \mathrm{I}$ per cent were land-based $(\mathrm{I}, 043,555)$ and 29 per cent $(435,515)$ were sea-based. 35 per cent $(362,878)$ of the land-based OFWs were new hires. Domestic workers comprised about 20 per cent $(7 \mathrm{I}, 557)$ of total new hires for 2009 , of which 97 per cent $(69,669)$ were women (Sobritchea/Subingsubing/Quesada 20IO: Io).

9 The Philippine government recognizes ten elements of reproductive health as follows: I) family planning information and services; 2) maternal, infant, and child health and nutrition; 3 ) prevention of abortion and management of abortion complications; 4) prevention and treatment of RTIs/STIs/ HIV/AIDS; 5) education and counselling on sexuality and sexual and reproductive health; 6) treatment of breast and reproductive tract cancers and other gynaecological conditions; 7) male involvement and participation in reproductive health; 8) adolescent and youth reproductive health; 9) elimination of violence against women and children; Io) prevention and treatment of infertility and sexual dysfunction. This chapter deals specifically with I, 3, 4, and 5 .

10 These include training, advocacy, and service programmes on the prevention of HIV and AIDS, the reduction of maternal deaths, and the promotion of education in adolescent sexuality. Sex education is now integrated into the curricula of secondary and public tertiary schools. varying degrees of effectiveness, because of the strong influence of faith-based organizations who only accept natural family planning methods. There has been erratic and uneven dissemination of SRH information across the country. Moreover, access to quality health services is constrained by high costs, inefficiencies in health care management, and socio-cultural norms. There is limited availability of contraceptives and poor dissemination of information on how to prevent early unwanted pregnancy, or the risk of pregnancy. The power of the church means that contesting the normative understanding on the relationship between sexuality and health and attempts to meet some of the critical SHR health needs of the population can only be negotiated between civil society organizations and local government institutions. For overseas workers, restrictions imposed by the host countries on the practice of non-national health professionals limit the ability of embassies and consulates to provide actual and direct medical services. They can only refer overseas workers to service providers in the host countries, or facilitate repatriation.

The scope for the government of the Philippines to take responsibility for ensuring migrant women domestic workers have access to SRH services does remain limited. The existing body of knowledge on SRH of migrant workers is too small and does not contain the hard data often required by policy-makers and programme implementers to institute the necessary services. Furthermore, there is an overwhelming concern among civil society organizations about labour issues, which is putting SRH rather in the shade on the government agenda. In destination countries faith-based organizations have been in the lead in raising SRH consciousness through programmes conducted with migrant workers and local authorities. Since they are at the bottom of the hierarchy of social worthiness, migrant domestic workers must rely on either their employers or faith-based organizations to recognize their right as persons to health and well-being.

\subsubsection{Regulating Domestic Work in Hong Kong, Singapore, and Qatar: Implications for Workers' SRH}

Hong Kong (Special Administrative Region of China), Singapore, and Qatar share the characteristic of being small in area yet having a large stock of international migrants as a percentage of the total population (Hong Kong 39 per cent; Singapore 4I per cent; Qa$\operatorname{tar} 87$ per cent), ${ }^{11}$ with a large proportion of them be- 
ing domestic workers. These workers are mainly from South Asia and South-East Asia. The three places enjoy the status of being among the richest in the world with excellent health care systems. That the presence of these migrant workers fills the labour gaps in lowskilled and low-paid sectors where work is too onerous by national standards has become common knowledge; less widespread is knowledge about the relationship between the presence of domestic workers and sending countries' labour export policies (Oishi 2005) and how the right to health is or is not ensured under such policies. Concerns are emerging about socio-demographic transition, family structures, and the ageing factor in these societies, especially in Hong Kong and Singapore (Huang/Yeoh 2005). Unless family policy can effectively address intergenerational care (Chiu/Wong 2009) the presence of domestic workers should be treated as a bilateral issue between sending and receiving countries rather than only from the perspective of individual choice and agency.

The migration system for domestic workers is based on a two-year period, with allowance for renewal for a period of the same duration. Of the three countries, Hong Kong is legally the most advanced in terms of ensuring labour standards for migrant domestic workers. They are protected by Chapter 57 of the Laws of Hong Kong, covering a comprehensive range of employment protection and benefits for employees $^{12}$ and by the Occupational Health and Safety Ordinance which ensures the protection of employees in the workplace regardless of citizenship or documentation status. ${ }^{13}$ The Race Discrimination Bill prohibiting discrimination, harassment, and vilification on the grounds of race introduced recently has had a limited effect on domestic workers, given the exception clause applicable in any work situation where fewer than five persons are employed. ${ }^{14}$ A related policy, the Sex Discrimination Ordinance, prohibits employers from doing the following: refusing to hire a

11 Figures are from IOM's (2010) World Migration Report, and fact sheets. See at: <http://www.iom.int/jahia/Jahia/ about-migration/facts-and-figures/lang/en> (accessed 7 May 2OI2).

12 Labour Legislation, Employment Ordinance, Chapter 57. See at: 〈http://www.labour.gov.hk/eng/legislat/content2. htm> (accessed Io November 2009).

13 Labour Legislation, Employment Ordinance, Chapter 57. See at: <http://www.labour.gov.hk/eng/legislat/ content2. htm> (accessed Io November 2009).

14 See at: <http://www.hg.org/article.asp?id=5324> (accessed 22 April 20I2). woman because of pregnancy; limiting a worker's transfer or training options because she is pregnant; firing or forcing a worker to leave because she is pregnant or on return from maternity leave; taking away credit for service because of maternity leave.

In Singapore foreign workers are classified by level of education and income, according to which the government grants permission for terms of residence. Employment passes are granted to foreign professionals whose monthly earnings reach a certain threshold set by the government; they are widely known as 'foreign talents'. At the lower end of the income/profession spectrum, employers are granted permits to take 'unskilled or semi-skilled' workers, whom Singaporeans refer to as 'foreign workers'. Foreign domestic workers are called "Foreigners in Our Homes" (Teo/ Piper 2009). The work permits are issued on the condition that the women do not marry Singaporeans nor become pregnant. Standard employment contracts in Singapore now state that registered employers must ensure medical care and treatment is covered for the duration of the employment. Foreign workers without valid work permits are unable to access the government health system to the same degree as those with permits, and they do not have access to a government health subsidy. In March 2012 the Manpower Ministry granted foreign domestic workers a weekly rest day. ${ }^{15}$

By contrast, Qatar has a very poor record in the treatment of foreign workers. They are excluded from Law I4 of 2004 that governs labour in the private sector, which limits working hours and sets requirements on paid annual leave, health and safety, and prompt payment of wages each month. Neither this law nor supporting legislation sets a minimum wage. The Law allows only Qatari workers to form unions, and permits strikes only with prior government approval. Qatar has I50 labour inspectors to monitor compliance with the labour law, though inspections do not include worker interviews. ${ }^{16}$

Excluded from the labour law as they are, foreign workers do not benefit from these provisions. Together with construction workers, domestic workers come under a 1963 'Sponsorship Law', known as the kafala system, which regulates their entry and employment. Under this system migrant workers cannot

15 See at: <http://www.hrw.org/news/20I2/03/05/singapore-domestic-workers-get-weekly-day-rest $>$ (accessed 20 July 20I2).

16 See at: 〈http://www.hrw.org/world-report-20I2/worldreport-2OI2-qatar> (accessed 22 April 20I2). 
change jobs without their sponsoring employer's consent, other than in exceptional cases with permission from the Interior Ministry. A Qatari company, which can be run by a private citizen or a foreign national, acts as the sponsor who procures a visa for a worker. The sponsor has effective control over the movements of their worker in Qatar for the duration of the contract. They frequently confiscate workers' passports, although this is in violation of the Sponsorship Law. The worker cannot leave the country, buy a car, or rent a home without the sponsor's permission. Although sponsors are required to give workers an endof-year bonus, a return airline ticket, and medical insurance, failure to do so is often not penalized. Nonobservance of requirements for minimum wage, overtime wage, and timely payment is common. Non-compliance which results in the disadvantaged employees leaving the job situation can be a basis for the employer to report the worker as 'having absconded', which leads to a threat of detention and deportation. ${ }^{17}$

Despite these variations in the legal treatment of migrant domestic workers in the three countries, socially these workers share a common condition of being confined to individual households as their place of work as well as residence. In Hong Kong and Singapore, where they are allowed to have a day off, their regular use of public spaces around the cities - to socialize and enjoy a brief moment of privacy away from their employers - has led to the formation of 'ephemeral enclaves' which have become an issue for local citizens who perceive this as a form of nuisance, inconvenience, or even threat. Markers of cultural and ethnic identities have emerged as a 'cordon' around the public spaces used; these are then avoided by local citizens (Koh 2009; Tillu 20II). Such is the powerful effect of cultural inscriptions on physical space. In Qatar some employers have allowed their domestic workers a day off every Friday, in principle to study Islam. This was the only way the domestic workers could spend time outside the house of their employers. ${ }^{18}$

17 Field findings of this research indicate that there are employers who allow domestic workers to use their cell phones and the Internet to communicate with their families and friends, to have some days off from work, and have a rest period during the day. Some of have been allowed to visit their families even before the end of their two-year contract. This latter experience may be attributed to having expatriate employers who were mostly Westerners, or for having served their employers for a long period of time.
It can be said that the social standing of migrant domestic workers within the hierarchy of foreign labour is defined by specific processes of inclusion and exclusion. The interplay between different identitieslegal, economic, political, and sociocultural-is accentuated in conjunction with gender, sexuality, ethnicity, and nationality (Yeoh/Huang 2000, 2010). One common concern is sexuality, where the condition of nonentry and expulsion includes medical 'unfitness', covering 'being pregnant' and having Sexually Transmitted Diseases (STDs), Acquired Immune Deficiency Syndrome (AIDS), or Human Immunodeficiency Virus (HIV). Once placed in their jobs, domestic workers must go through periodic mandatory health checks for specific SRH (Guild/Mantu 20II: 80-IO3). Birth prevention during migration, with all the legal and medical risks involved, is left to a migrant's discretion.

In response to incidents of abuse of migrant domestic workers that have been made public, faithbased institutions in Hong Kong and Singapore have played a critical role in providing immediate assistance to those who have escaped from their workplaces and agents, and in setting up other services for those who remain employed. The Catholic Church has pioneered the giving of assistance to Filipino migrant workers. The increased diversification of ethnicity and nationalities among the population of migrant workers has led to mosques and Buddhist temples also providing programmes for them which include religious education and recreational activities. There has also been a rise in the number of Non-Governmental Organizations (NGOs) active in lending support and assistance to migrant workers. ${ }^{19}$ It is also important to note that the general consciousness of SRH in Hong Kong promoted under the Family Planning Programme $e^{20}$ is resulting in some direct benefits for migrant domestic workers, as will be shown in the next section.

18 Our field research has noted a number of cases of domestic workers ostensibly converting to Islam to benefit from this allowance.

19 Some major organizations are: I) HOME, a recognized institution that responds to the needs and concerns of migrant workers in the country; 2) the Transient Workers Count Too (TWC2), which works to improve the lives of domestic workers in Singapore through research, advocacy, and the provision of direct services; 3) Aidha, a charitable non-governmental organization focusing on organizing part-time financial and businessrelated courses for domestic workers. 
The SRH experience of migrant domestic workers can be seen as contingent on the nature of domestic work and its formal and informal regulations, the cultural framing of sexuality, and social understanding of their bodies. Identity construction processes selectively emphasize 'gender' in heterosexual terms that are intersected by the workers' ethnic, religious, and class identities, making the subject of control so intricate that interpretation of SRH norms must take serious note of the contextual articulations of power relations.

\subsection{Individual SRH Problems and Intersecting Power Relations}

The data discussed in this section were gathered from seven in-depth interviews in a broader research involving I47 Filipina domestic workers and twenty-nine interviews with key informants in Hong Kong, Qatar and Singapore. Three participants in focus group discussions (FGDs) experienced reproductive health ailments and were interviewed at length as case studies. Local research partners further identified four other domestic workers who had experienced sexual and reproductive health problems as case study informants. In-depth interviews generated important information on how the women dealt with their health problems, given their knowledge of and attitudes towards health and conditions of work. A key point that has emerged is the intersection of individual SRH problems with various facets of institutional exclusion.

SRH services are generally available in all three study sites, but financial and social barriers to access are the major problem. Policies on certain sexual and reproductive health issues differ between the three study sites. Abortion is legal in Hong Kong and Singapore within specific parameters: it has to be performed by a doctor; the woman has to undergo counselling and a medical going-over performed by at least two physicians who approve the procedure. In Qatar abortion is illegal. Though all three countries have policies on health insurance applicable to migrant domestic workers for the duration of their employment

20 This consciousness has helped ensure quality reproductive health care for citizens, as reflected in the low rate of maternal mortality. In Singapore the rate is 9 per I00,०००. While there is no separate figure for Hong Kong, the equivalent statistic for China is 38, for Qatar 8, and for the Philippines 94. See at: <http://data. worldbank.org/indicator/SH.STA.MMRT> (accessed 9 May 20I2). contract, information gathered from fieldwork suggests it is mainly only workers in Hong Kong who enjoy this privilege. In Singapore there were participants who had insurance and there were those who said they didn't. There were also participants who did not know they were supposed to have health insurance. This was common among the participants in Qatar; those who could access medical services emphasized the instigating role of the employers.

Nearly all the interviewed domestic workers belonged to the reproductive age group. Sixty per cent of the total number of research participants belonged to the 20-39 age group; thirty-eight per cent were between 40 and 59. One domestic worker was under twenty; one other was over sixty. There were slightly more in the older age bracket in Singapore and Hong Kong compared with those in Qatar. Forty-five per cent were unmarried, forty-two percent married, eight per cent had separated, and the rest were widows. The relatively younger average age of domestic workers in Qatar could be explained by the fact that recruiters specifically target young women from rural areas in the southern part of the Philippines. The rapid processing of documents allowing them to leave within a month's time and the fact that the agents do not collect placement fees were cited as the main reasons.

More than half the research participants had children, ranging in number from one to nine. One in three of the mothers had only one child; forty-one per cent had two to three, and twenty-six per cent four or more. The higher percentage of women who had fewer than four children can be explained by the relatively young age of the majority. The data on the number of years of work abroad indicate that more than half of the research participants had been out of the country for less than five years; forty-four per cent had been abroad and separated from their families for six to twenty years. Female domestic workers continued to bear children throughout the cycle of their overseas employment. This finding reveals their dire need for regular access to reproductive health information and services.

Many FGD participants mentioned suffering repeated physical battery and verbal abuse not only from their employers but also from the latter's 'spoiled' children. Heavy workloads and close monitoring emerged as being of greatest concern.

The family took me on 'vacation' to Jordan to visit siblings. I had to clean three houses because my employer's siblings didn't have a maid. (Case study participant, Qatar). 
Although Hong Kong mandates a 24-hour day off for domestic workers, some employers expected the worker to be continuously active during working days. One reported being followed around by her employer's mother-in-law with a monitoring camera, and never allowed to sit down between tasks. In her words:

You go to the toilet not because you have to urinate but so you can have a little rest. You sit down and lean back and close your eyes, and in that way you get rid of some of your drowsiness. (An FGD participant, Hong Kong).

One worker who benefited from health leave told the following story:

Yes, I got seven day's leave after my surgery, but I still had to do some sweeping. (An FGD participant, Hong Kong).

Even when they were maltreated, very few went to the authorities to complain. They were afraid that their contract would be terminated as a consequence. In the words of one interviewee, a member of a supporting organization:

Especially when they're new, they're thinking about the debts they've incurred, they're thinking about their families who are waiting for their remittances. So even when they get sick, they just continue working. ... This is something that I wish our government would do something about.

Many put up with the maltreatment because they feared losing their jobs. The participants spoke of domestic workers who were fired for becoming ill or pregnant. As this kind of termination is illegal in Hong Kong, some employers there have waited until the worker has gone through surgery or come back from a hospital confinement, and then found some other reason for dismissing them. One of the key informants in the study, an expatriate employer in Hong Kong who serves as a volunteer for the organization 'Helpers for Domestic Helpers', said that she has known of women whose employment contracts were terminated in just that way. In her words:

[The employers] do this for their own convenience. ... They don't want someone who is slowed down, or tired or whatever, because they're pregnant. Or they don't want someone who's not doing their job as efficiently because they're unwell.

One FDG participant revealed that while on vacation in the Philippines she got married and returned to work pregnant. She asked permission to return home. Her employer told her to go to a doctor and ask for a particular medicine. The worker did not know it was an abortifacient. She got angry with her employer be- cause she had wanted to keep the baby. The president of the Asia Pacific Mission for Migrants shared the following:

Some employers tell their maids 'Don't get pregnant'. Should they even have a say in that area of your life?... It's your right, as a woman, as a married person, to have a child if you want to. But because you are a domestic helper, and your employer doesn't want you to get pregnant, you follow their order. But they are stepping on your right to form a family.

Exclusion from SRH education emerged as a key point of issue affecting health-seeking behaviour. The level of SRH awareness among interviewees varied but was generally very low and included a number of misconceptions with consequences for their health. Traditional gender norms, which dictate that women should remain ignorant about matters pertaining to sex and sexuality, reinforce their exclusion from SRH education. A sense of discomfort surged among some of the FGD participants when these matters came up for discussion as they were considered shameful. Even when they experience SRH problems they find it uncomfortable to talk to their friends, and even more so to a male doctor who is not even a Filipino. Going for a medical examination that would involve showing a doctor their private parts is even more unthinkable. As a result, a simple infection of the reproductive tract can become serious because only when their condition has worsened do they find the courage to make mention. Those who talked with more comfort about the matters related to sex and SRH were older and had worked in the study sites longer. They did not mind sharing intimate experiences such as masturbation and showing the younger women in the group that they should learn to be more comfortable about issues of sexuality, reject taboos, and accept these issues as a normal part of life.

Some FGD participants admitted to engaging in sexual relationships while in their country of employment, divulging also that they used condoms. They did not always seek medical attention or health services when they felt sick. They kept their conditions to themselves and endured pain and discomfort in silence for fear that their contracts would be terminated if their employers were to find out and they would be sent home.

The case of a 44-year-old unmarried domestic worker in Qatar shows the detrimental consequences of inadequate SRH education.

I met him through a friend. After a year of casual friendship we had a sexual relationship. We both wanted it to happen but we didn't think about using protection 
because it never occurred to us that I would get pregnant. Besides, my menstruation still came every month. I didn't notice that my abdomen was getting bigger because I have always been fat. One time I noticed it was hard to the touch. I told my employer about it, but she dismissed it as merely gas pains. I also ignored it. Then one evening after going out with my employer's family I felt an excruciating pain in my abdomen. I thought it was a very bad stomach ache. My employer took me to the doctor, who injected me with medicine and gave me some tablets to take. After that we went home. That night I couldn't sleep. The pain was persistent. I slept in the bedroom of my employer's children and they noticed I was crying in pain. They told their mother so my employers took me back to the hospital. Doctors took my x-ray and tested my urine. That's how they found out that I was pregnant and that I was already in my ninth month, which was a big surprise to me because I never missed my period. I did not experience any morning sickness otherwise my employer would have noticed and would have taken me to the hospital sooner. (Case study participant, Qatar).

Birth prevention through self-medication is widespread. A health official in Hong Kong revealed the prevalent use of Cytotec (misoprostol or synthetic prostaglandin E1 $)^{21}$ for the purpose of termination of pregnancies. In Hong Kong and Singapore any method of inducing abortion that does not follow the regulated protocols of medical abortion is considered illegal. To keep the knowledge of their pregnancy to themselves, domestic workers use Cytotec because it can induce abdominal contractions, which may result in labour. One domestic worker was jailed in Hong Kong for trying to abort a foetus that was more than twenty-four weeks old by taking Cytotec.

Cyctotec has a low rate of success as an abortifacient, simply because users do not have accurate information about dosage and proper administration. The FGD participants were aware that "if it only causes you to bleed and you don't abort completely it may result in more complications". One case study informant, who had terminated a pregnancy using Cytotec, believed this was why she developed myoma (fibroids). "Not all the blood came out and that is what grew into a tumour." Myoma became a topic of discussion.

It's what we talk about when my friends and I get together. It's our number one question: why do so many

21 WHO currently includes misoprostol (Cytotec) in its evidence-based guidelines and Model List of Essential Medicines for early pregnancy termination together with mifepristone, medical management of miscarriage, and labour induction. See at: 〈http://whqlibdoc.who. int/hq/20IO/WHO_RHR_IO.II_eng.pdf> (accessed 9 May 20I2). of us have myoma? Is it from being on our feet the whole day? (Case study participant, Hong Kong).

There have been many instances when an employer will say, after the domestic worker has gone to the doctor two or three times:

Okay, I think that it's better that you return to the Philippines and rest. (FGD participant, Hong Kong).

The fear of being sent home for having SHR problems can be reinforced by financial limitations. ${ }^{22}$ In most cases FGD participants gave priority to saving for remittances over spending their salaries to care for their own health. They rely on self-medication-bringing medicines with them from the Philippines; medicines they are familiar with that can be bought over the counter; medicines for pain, fever, colds, coughs, and diarrhoea. If they run out of these medicines they rely on non-prescription medicines without first consulting a doctor.

Though exposure to education programmes organized during pre-departure orientation seminars as well as in the country of destination does make a difference in the level of SRH consciousness (as also does sharing experiences with their peers), their access to SRH services in destination countries depends largely on their employers. The existence of policies enabling workers to access health services in general or SRH services in particular can facilitate such access but does not guarantee it. In Hong Kong, for example, employers of migrant domestic workers are required by law to ensure that their workers have a valid Hong Kong Identification Card (ID) allowing them access to government hospitals and medical services at a very affordable rate. However, a domestic worker, though in possession of this ID card, may not be able to readily reach any health facility if her employer does not allow her to leave the house at any time except on Sundays.

Having a good relationship with their employers can greatly facilitate workers' access to health services. It makes it easier for a worker to inform her em-

22 The Philippine government requires employment agencies to prescribe a minimum monthly salary of US\$400 for departing domestic workers but the findings show widespread violation of this regulation. Except for those in Hong Kong and for some in Singapore, there are many deployed domestic workers who are not getting the prescribed minimum salary. Some departing domestic workers are made to sign an employment contract before they leave that conforms to this policy and then made to sign another employment contract specifying a much lower monthly salary once they are abroad. 
ployer if she gets sick and asks permission to go to the hospital, or even to go on leave after a serious illness. Responses from the employers do vary though. Some participants in FGDs stated that their employers took care of them when they got sick; others said that despite a good relationship with their employers they still had to work right after getting home from time in hospital. Employers depended on them to keep the house in order and make sure the children were taken care of.

One study participant was diagnosed with breast cancer, requiring treatment by chemotherapy, for which reason her employer fired her. In Hong Kong the worker could have filed a case against her employer for terminating her contract due to an illness, but most of the time the domestic workers do not pursue such cases. They would actually rather go back to the Philippines.

I am worried because the doctor said that the chemotherapy is not totally free of charge and I will have to pay a portion of the cost. I know I won't be able to afford this because my employers terminated my contract. I don't blame them. They have been very good to me and call me to ask how I am. But they do not have a lot of money so they cannot afford to support me. If I were to stay with them, I would n't be able to fulfil my duties, yet they would be required to pay me. How will they manage? This is why they had to let me go. ... I need to have my visa extended so I can continue having my treatment in Hong Kong. The Immigration Department has already extended my visa for three months. ... Immigration officers told me that I could demand support from my employer. They said I could file a case against them with the Labour Department because in Hong Kong, an employer cannot terminate a domestic worker if she is undergoing treatment. I know this but I don't want to file charges against my employer. I love this family. (Case study in Hong Kong.)

Apart from the kind of relationship they have with their employers, the influence of family and friends also counts. In many instances the family in the Philippines, as well as friends, can serve as facilitating factors for migrant domestic workers to access SRH services. They can positively influence health-seeking behaviour by giving information on where to get help, and can also provide emotional and moral support. When they share positive experiences with health care facilities in the host countries, family and friends can effectively encourage them to continue to seek these services. If they share negative or traumatic experiences, family and friends may discourage or even scare them off from pursing their case. In the words of a rape victim in Qatar:

My employer has actually offered to pay me five thousand riyals and buy me a ticket back to the Philippines to have me shut up. But he can't just pay me off for what he's done to me. I really want to pursue this because he took my virginity. I find this very hard to accept. And I am waiting for my next period. What if he has gotten me pregnant? Then it would be even more difficult for me to accept. My mother in the Philippines now knows what has happened to me. She wants me to go home but I told her that I want to pursue and win this case, though the people here at the Embassy have told me these criminal cases take time, maybe two years. (A case study in Qatar.)

In Hong Kong and Singapore there are NGOs and migrant organizations who serve as support groups for migrant women domestic workers. These institutions can be sources of SRH information and services. They can also reinforce positive health-seeking behaviour through awareness-raising activities. FDG participants generally experienced positive treatment by the medical and health care personnel when in a hospital or clinic in the destination country, though some felt that the doctors did not spend enough time on them to find out what their ailments really were. They felt they were rushed through the consultation and were simply given pills without any explanation of what the pills contain or what they were supposed to be curing.

Communication barriers are another issue when being dealt with by health care personnel. Participants in Hong Kong and Singapore confided that, because of colloquial usage, they couldn't understand what their doctors were saying even though they were speaking in English. Hong Kong's Racial Discrimination Ordinance provides for meeting a patient's request to have an interpreter when accessing services in a hospital. The problem was that the migrant workers were not aware of this policy and so remained frustrated by the difficulties in communicating with medical and health care personnel. In Qatar, there were domestic workers who noticed that the doctors treated them better when their employers were with them during a visit to the hospital. They felt that they were not treated as well when on their own and believed that they were discriminated against because they were domestic workers. A number of the study participants also said that the nurses looked down on them because they were just migrant domestic workers.

The diverse experiences of Filipina domestic workers with $\mathrm{SRH}$ problems concerning access to services, and the limited scope of this research, do not permit taking any firm position on the causal relationship between migration and SRH, especially regarding the intersection of individual medical problems with social inclusion/exclusion. What has become clear is that migrants do not leave their sexual 
lives behind them when they cross borders for work and also that the institutional context of labour regulations matters a great deal in their SRH health-seeking behaviour. Yet the rigorous pregnancy control of domestic workers seems to manifest a social consciousness about female efficiency, but efficiency that must be delivered by a body that is supposed to remain infertile. This has implications for the emerging research field of migration and SRH, both theoretically and practically.

\subsection{Conclusion}

As an emerging issue in global migration, SRH research in the Philippines still has a long way to go to come up with policy messages useful for setting up services to groups of migrants whose health has been affected by the ways their migration is organized. Findings on overseas domestic workers from the Philippines in this study show how power relations can be articulated in ways that shape their structural vulnerability to SRH problems. The articulation depends greatly on context and place irrespective of the fact that the three countries share the common denominator of an excellent health system. Most significantly, the link between the SRH problems experienced by a migrant domestic worker as an individual and the mechanisms of exclusion from, or inclusion in, SRH services operates simultaneously at ideational and material levels. Ensuring affordable services is not enough; gaining awareness and knowledge about the right to exercise the right to SHR health seems crucial, particularly among migrant domestic workers whose health-seeking behaviour is constrained by conventional norms of sexuality and a range of choices that are far from risk-free.

International migration connects countries of origin, transit, and destination, and it is important for governments to recognize the complex intersection between migration systems and health systems. A purely national approach to migration and health is too limited to respond to the health needs of migrant workers. Bilateral, multi-country, and multi-sectoral dialogues would help foster collaboration and partnership to harmonize the responses to these needs. Various regional and subregional forums addressing transnational health challenges such as HIV and AIDS, SARS, avian influenza, and the $\mathrm{H} 1 \mathrm{~N} 1$ virus are already in place. Efforts to address migrants' health, and in particular SRH, must take note of the specific structural vulnerability they are subject to and recog- nize the intricate workings of power over the female human body. Such power intersects with a wide range of institutional practices and has consequences for their health.

Over the next few decades international migration is likely to be transformed in scale, reach, and complexity due to growing demographic disparities, the effects of environmental change, new global political and economic dynamics, technological revolutions, and evolving social networks (IOM 20IO). The sheer magnitude of the movement and flow of persons in a given region and throughout the world necessitates critical discussion on the health aspects of migration. Depending on the situation and location, the health of migrants may have important implications for the populations from which they originate, through which they travel, and where they live and work. At the same time aspects of migrants' health are influenced and affected by how they travel and to what destination, and where they temporarily reside or permanently settle (Gushulak 20I0).

Addressing migrants' health involves integrating key human rights concepts into sound public health approaches. The key is to eliminate disparities in access to health services, facilities, and goods between migrants and host populations, bearing in mind the financing implications for existing health systems. It implies the creation of an environment that enables migrants to enjoy their full rights, which must include those of sexual and reproductive health. This will need to be done along with proactive strategies that address the totality of migrants' human rights. In the area of migrants' SRH it is important to continue generating more evidence. This should include further investigation and analysis of trends and patterns in the SRH status of migrant workers, the mapping of existing SRH services, policies, and information, and identification of good practices in addressing migrant workers' SRH needs. Qualitative evidence of needs articulated through the voices of migrants is crucial to improving existing SRH programmes and services. As Marin (2OI2) emphasizes, the gathering, dissemination, and utilization of information must take into account issues of human security such as security of identity, since disclosure of sensitive data or information about migrants could put them in a precarious situation. This is especially true in the case of irregularly documented migrants, for whom a more nuanced approach will be required. 


\section{References}

Bourdieu, Pierre, 2000: Distinction: A Social Critique of the Judgement of Taste (Cambridge, Mass.: Harvard University Press).

Chiu, Stephen Wing-kai; Wong, Richard Ka-chung, 2009: A Literature Review on Family Policy in Four East Asian Countries (Hong Kong: The Chinese University of Hong Kong).

Derose, Kathryn Pitkin; Escarce, José J. Lurie, Nicole, 2007. "Immigrants And Health Care: Sources Of Vulnerability", in: Health Affairs, 26,5: 1258 -I268.

Dwyer, James, 2004: "Illegal Immigrants, Health Care, and Social Responsibility", in: Hastings Center Report, 34,r: 34-4I.

Farmer, Paul, 2004: Pathologies of Power: Health, Human rights, and the New War on the Poor (Berkeley: University of California Press).

Foucault, Michel, 1979: The History of Sexuality Volume I: An Introduction. Translated by Robert Hurley (London: Allen Lane).

Galtung, Johan, I990: "Cultural violence“, in: Journal of Peace Research, 27,3: 29I-305.

Glasier, Anna; Gülmezoglu, A. Metin; Schmid, George P.; Moreno, Claudia Garcia; Van Look, Paul F.A., 2006: "Sexual and Reproductive Health: a Matter of Life and Death" in: Lancet, 367. 1595-1607.

Guild, Elspeth; Mantu, Sandra, 20II. Constructing and Imagining Labour Migration: Perspectives of Control from Five Continents (Burlington, VT: Ashgate).

Gushulak, Brian, 20I0: "Monitoring Migrants' Health". Paper presented at the WHO-IOM Global Consultation on Migrant Health. Madrid, Spain. March 2010.

Huang, Shirlena; Yeoh, Brenda, 2003: "The Difference Gender Makes: State Policy and Contract Migrant Workers in Singapore", in: Asia and Pacific Migration Journal, I2,I- 2: $75-98$.

IOM (International Organization for Migration), 20I0: World Migration Report 2010 (Geneva: IOM).

Koh, Cha-Ly, 2009: The Use of Public Space by Foreign Female Domestic Workers in Hong Kong, Singapore and Kuala Lumpur (Cambridge, Mass.: Massachusetts Institute of Technology).
Lorant, Vincent; Van Oyen, Herman; Thomas, Isabelle, 2008: "Contextual factors and immigrants' Health Status: Double Jeopardy", in: Health \& Place, I4,4: 678692.

Marin, Maria Lourdes S., 20I2: "Navigating Borders, Negotiating Bodies: Sexual and Reproductive Health and Rights of Women Migrant Workers". Paper presented at "Beyond ICPD and MDGs: NGOs Strategizing for Sexual and Reproductive Health and rights in Asia-Pacific. Kuala Lumpur, Malaysia, 3-5 May $20 I 2$.

Oishi, Nana, 2005: Women in motion : globalization, state policies, and labor migration in Asia (Stanford, Calif.: Stanford Univ. Press).

Quesada, James; Hart, Laurie Kain; Bourgois, Philippe, 20II: "Structural Vulnerability and Health: Latino Migrant Laborers in the United States", in: Medical Anthropology, 30,4: 339-362.

Sobritchea, Carolyn I.; Subingsubing, Dino Alberto; Quesada, Amara T., 20Io: Health of our Heroes Access to Sexual and Reproductive Health Services and Information of Women Migrant Domestic Workers (Quezon City: Action for Health Initiatives [ACHIEVE] Inc.)

Teo, Youyenn; Piper, Nicola, 2009: "Foreigners in Our Homes: Linking Migration and Family Policies in Singapore", in: Population, Space and Place, 15,2: I47-159.

Tillu, Jasmine S., 20II: Spatial Empowerment: The Appropriation of Public Spaces by Filipina Domestic Workers in Hong Kong (Cambridge, Mass.: Massachusetts Institute of Technology).

World Health Organisation, 20Io: Health of Migrants: the Way Forward - Report of a Global Consultation, Madrid, Spain, 3-5 March 2010 (Geneva: WHO).

World Health Organization, 2008: Secretariat Report. Health of Migrants, $6 I^{\text {st }}$ World Health Assembly (Geneva: WHO).

Yeoh, Brenda S. A.; Huang, Shirlena, S. L., 2000: “Home' and 'away': Foreign Domestic Workers and Negotiations of Diasporic Identity in Singapore", in: Women's Studies International Forum, 23,4: 413-429.

Yeoh, Brenda S. A.; Huang, Shirlena, S. L., 20I0: "Sexualised Politics of Proximities among Female Migrants in Singapore”, in: Population, Space and Place, 16,1: 37-49.

Open Access. This chapter is distributed under the terms of the Creative Commons Attribution Non-commercial License, which permits any noncommercial use, distribution, and reproduction in any medium, provided the original author(s) and source are credited. 